\title{
A GRAMÁTICA FONOLÓGICA NA AQUISIÇÃO DA LINGUAGEM
}

\section{LA GRAMÁTICA FONOLÓGICA EN LA ADQUISICIÓN DEL LENGUAJE}

\author{
THE PHONOLOGICAL GRAMMAR INLANGUAGE ACQUISITION
}

\section{Carmen Lúcia Barreto Matzenauer*}

Universidade Federal de Pelotas

RESUMO: O artigo trata do processo de construção do conhecimento fonológico na aquisição típica da linguagem pelas crianças, evidenciado mais especificamente pela variabilidade no emprego de consoantes até a integralização do inventário fonológico da língua alvo. Uma análise fundamentada em traços distintivos e centrada no comportamento de consoantes líquidas confirma a hipótese de que a variabilidade, entendida como o uso de diferentes formas fonéticas para representar um mesmo segmento fonológico em gramáticas características do gradual processo de aquisição, oferece evidência de que o pertencimento a uma classe antecede a estabilização do segmento como unidade da fonologia da língua. Os dados empíricos de variabilidade, enriquecidos pela observação do preenchimento de lacunas nos estágios mais precoces de aquisição, secundados pelo comportamento de empréstimos linguísticos, conduzem à proposição de uma Escala de Agregação para expressar uma hierarquia relativa à força dos traços no cumprimento do papel de agregar segmentos para a constituição de classes naturais.

PALAVRAS-CHAVE: Aquisição fonológica. Variabilidade. Consoantes líquidas. Traços e classes de segmentos. Escala de Agregação.

RESUMEN: El artículo trata del proceso de construcción del conocimiento fonológico en la adquisición del lenguaje por niños, evidenciado, más específicamente, por la variabilidad en el empleo de consonantes hasta la integración del inventario fonológico de la lengua meta. Un análisis fundamentado en rasgos distintivos y centrado en el comportamiento de consonantes líquidas confirma la hipótesis de que la variabilidad, entendida como el uso de diferentes formas fonéticas para representar un mismo segmento fonológico en gramáticas características del proceso gradual de adquisición, ofrece evidencia de que la pertenencia a una clase antecede a la estabilización del segmento como unidad de la fonología de la lengua. Los datos empíricos de variabilidad, enriquecidos por la observación del relleno de vacíos en las estapas más precoces de adquisición, apoyados por el comportamiento 
de préstamos lingüísticos, conducen a la proposición de una Escala de Agregación para expresar una jerarquía relativa a la fuerza de los rasgos en el cumplimiento del papel de agregar segmentos para la constitución de clases naturales.

PALABRAS CLAVE: Adquisición fonológica. Variabilidad. Consonantes líquidas. Rasgos y clases de segmentos. Escala de Agregación.

ABSTRACT: This paper deals with the construction process of phonological knowledge in children's typical language acquisition, which is mainly shown by variability in the use of consonants up to the completion of the target language phonological inventory. An analysis based on distinctive features and centered on the behavior of liquid consonants confirms the hypothesis that variability - understood as the use of different phonetic forms to represent a single phonological segment in grammars which are characteristic of the gradual acquisition process - shows that belonging to a class precedes the stabilization of the segment as a unit of a language's phonology. Empirical data on variability, enriched by the observation of gap filling in the earliest stages of acquisition and supported by the behavior of linguistic loans, lead to the proposition of an Aggregation Scale to express a hierarchy related to the strength of features when they play the roles of aggregate segments for the constitution of natural classes.

KEYWORDS: Phonological acquisition. Variability. Liquid consonants. Features and classes of segments. Aggregation Scale.

\section{INTRODUÇÃO}

O foco deste estudo ${ }^{1}$ é o processo de construção do conhecimento fonológico na aquisição da língua materna pelas crianças, evidenciado mais especificamente pela variabilidade no emprego de consoantes até a integralização do inventário fonológico da língua alvo.

As análises voltadas para o problema do desenvolvimento linguístico da criança identificam estágios de aquisição, sendo que corresponde a cada estágio uma organização das unidades da língua, ou seja, uma gramática. No plano fonológico, a formação gradual do inventário de segmentos, tanto de segmentos vocálicos como consonantais, oferece evidências claras de diferentes estágios desenvolvimentais. A variabilidade, ou seja, o emprego simultâneo de mais de uma forma fonética para representar um mesmo segmento fonológico, é ocorrência característica de estágio que antecede a estabilização da relação entre forma fonética e forma fonológica correspondente ao funcionamento da língua alvo da aquisição.

Como exemplo, trazem-se, em (1), dados da menina Leila ${ }^{2}$ que, com a idade de 2:4 (anos: meses), mostra variabilidade na representação fonética do fonema /r/ pelo uso das formas $[1, j, \mathrm{R}, \mathrm{r}]$, o que aponta estar a criança em fase de construção do mapeamento dessa rótica em seu sistema fonológico:

(1)

$\begin{array}{lll}\text { Informante } & \text { Output da criança } \\ \text { Leila }(2: 4) & \text { barata } & \text { [balate }] \\ & {[\text { ba'jate }]} \\ & {[\text { ba'sate }]} \\ & {[\text { ba'rate }]}\end{array}$

\footnotetext{
${ }^{1} \mathrm{O}$ presente texto está vinculado a resultados de pesquisa desenvolvida com o apoio do CNPq - Processo nº 305514/2013-0.

${ }^{2}$ Os nomes atribuídos às crianças, neste estudo, são fictícios.
} 
Dois pontos cruciais estão subjacentes à existência de variabilidade no uso de formas segmentais em um estágio da aquisição fonológica:

(a) o processo de aquisição de segmentos fonológicos da língua é gradual;

(b) os segmentos são multifacetados, ou seja, são o resultado da coocorrência de diferentes propriedades, de caráter articulatório e acústico, interpretadas por categorias abstratas que podem ter função na gramática da língua.

O ponto destacado no item (b) está na base do fato de um mesmo segmento fonológico poder ser representado por mais de uma forma fonética. Essa realidade tem relevância, porque expressa a complexa natureza do segmento: constitui-se em uma unidade da língua composta de outras unidades menores, ou seja, reflete a realidade de que cada segmento é a síntese de uma série de propriedades. No continuum fonético-fonológico presente em um sistema linguístico, cada segmento, sob o ângulo fonético, é o resultado da coocorrência de propriedades físicas (articulatórias e acústicas), efetivando-se como um contínuo fonético; sob o ângulo fonológico, é o resultado da coocorrência de propriedades abstratas (que atribuem uma categoria às propriedades físicas), cumprindo um papel na gramática.

O mapeamento das propriedades fonéticas em categorias da gramática fonológica é efetivado por traços; no nível fonológico, são distintivos e, de forma coocorrente, constituem as unidades segmentais também distintivas, reconhecidas como fonemas. Traços e segmentos são, pois, unidades cuja natureza contém noção fundamental para o funcionamento dos sistemas linguísticos: a noção de contraste, de distintividade.

Tem-se, em (2), uma formalização simplificada do mapeamento da forma fonética em forma fonológica: representam-se os traços como parte da gramática fonológica (sua face fonológica), mantendo também vínculo com propriedades físicas dos sons (sua face fonética) - os traços são a unidade da gramática que promove o contato com as propriedades físicas dos sons das línguas.

(2) Formalização simplificada do mapeamento da forma fonética em forma fonológica, mediado por traços
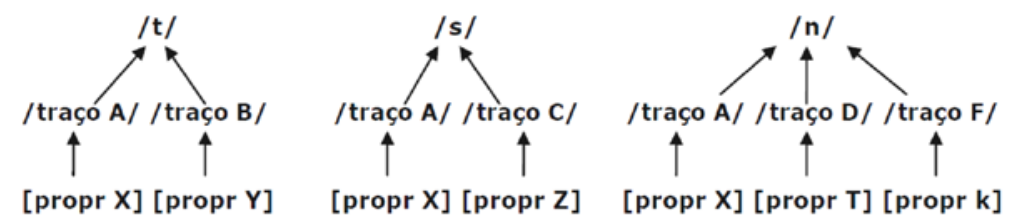

São os traços, portanto, a unidade de duas faces que organiza o nível fonético no nível fonológico dos sistemas linguísticos.

A natureza estrutural múltipla de cada segmento tem uma consequência importante na organização da gramática: vincula-o a mais de uma família/categoria de segmentos. Veja-se o exemplo em (3): o segmento /b/, por sua estrutura interna conter, entre outros, os traços [-soante, -contínuo, labial, +voz], coloca-o em diferentes famílias/categorias.

(3) Exemplo do segmento /b/, com a definição de alguns traços que compõem a sua estrutura e das famílias/categorias de segmentos a que pertence em razão de cada traço

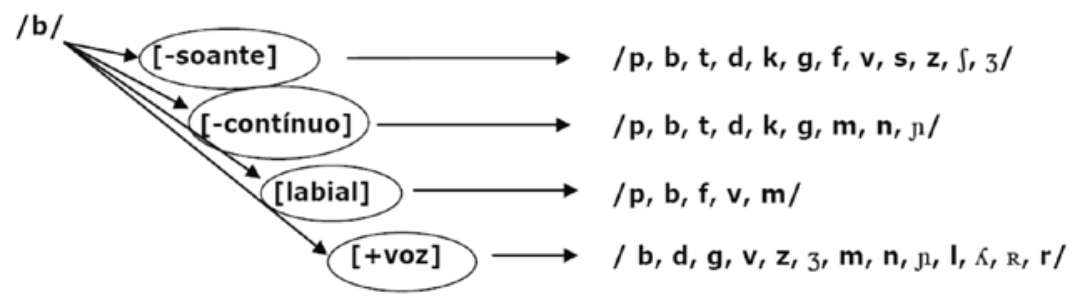


Ao se considerarem coocorrências de traços, essas famílias/categorias podem ser reestruturadas e, como consequência, podem ter a composição alterada - por exemplo, a categoria constituída pelo traço [+voz], mostrada em (3), é diferente daquela constituída pela coocorrência de traços [-soante, +voz], apresentada em (4).

(4) Exemplo do segmento /b/, com a definição da coocorrência de dois traços e a família/categoria de segmentos a que pertence

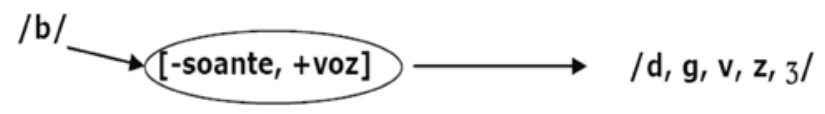

As famílias/categorias, que são identificadas como classes de segmentos, têm especial relevância nas fonologias das línguas porque são a base de seu funcionamento, no sentido de que processos fonológicos apenas se aplicam a classes de segmentos.

Têm-se classes de segmentos, explica Hyman (1975, p. 139-140), quando um ou mais dos seguintes critérios são verificados na língua:

a) os dois segmentos sofrem processos fonológicos juntos (ou seja, os dois segmentos são o input da regra);

b) os dois segmentos funcionam juntos nos ambientes de processos fonológicos (ou seja, os dois segmentos integram o contexto em que a regra é aplicada);

c) um segmento é convertido no outro segmento através de um processo fonológico;

d) um segmento é derivado no ambiente do outro segmento (como nos casos de assimilação).

Ao verificar-se que classes de segmentos têm a fonte de sua constituição em traços e que processos fonológicos apenas operam em classes de segmentos, é possível entender-se que, para a arquitetura da gramática fonológica de qualquer língua, as noções de traços e de classes de segmentos são fundamentais. E esse fato é relevante não apenas para o funcionamento das gramáticas das línguas, como também para o processo de aquisição fonológica, sendo ainda basilar para o entendimento da variabilidade segmental como parte desse processo.

Se, na gramática da língua alvo da aquisição (seja de L1 ou de L2), cada segmento está vinculado a determinada(s) classe(s), algumas questões, então, logo se impõem. Dentre elas, arrolam-se duas:

(a) Será que, desde o mais precoce estágio de aquisição, a criança categoriza os segmentos nas mesmas classes fonológicas que funcionam na gramática do adulto?

(b) Como se organiza a gradual expansão do inventário de segmentos: emerge o segmento ou, antes dele, emerge a classe fonológica, determinada por certo(s) traço(s)?

A observação de dados empíricos de crianças em processo de aquisição do Português Brasileiro (PB) levou a levantar-se a hipótese de que a emergência e a expansão do inventário de consoantes ocorrem a partir de classes circunscritas por traços fonológicos: os traços são capazes de dar base a uma classe e essa classe abarca segmentos. 
Tem-se, pois, o objetivo de saber a forma como essa construção do conhecimento fonológico acontece e, de modo particular, o papel de classes de segmentos na constituição de inventários fonológicos. O ponto de partida está no entendimento de que é como parte integrante da classe que os segmentos se organizam como unidades da gramática e:

(a) ocupam o seu próprio espaço fonético-fonológico;

(b) ocupam o(s) espaço(s) - lacunas - de outro(s) segmento(s) de aquisição mais tardia dentro da mesma classe;

(c) mostram emprego variável com outro(s) segmento(s) de aquisição mais tardia dentro da mesma classe.

O fenômeno da variabilidade ocorre como parte da organização de uma gramática que integra o processo de aquisição fonológica e isso acontece dentro de uma classe de segmentos, como integrante do conhecimento fonológico de classes de segmentos, as quais, conforme já foi explicitado, são definidas por traços fonológicos.

Como decorrência, neste estudo partiu-se da hipótese de que a variabilidade oferece uma evidência de que o pertencimento a uma classe antecede a estabilização do segmento como unidade da fonologia da língua. Pode dizer-se que, na aquisição, a classe domina/antecede o segmento.

Buscaram-se dados de aquisição fonológica para testar-se a hipótese aqui proposta.

\section{A OBSERVAÇÃO DOS DADOS DE AQUISIÇÃO FONOLÓGICA NESTE ESTUDO}

Os dados empíricos que serviram de fundamento para a discussão deste estudo foram coletados transversalmente junto a trinta crianças com desenvolvimento linguístico considerado típico, com idade entre 2:0 e 2:9 (anos: meses), falantes nativas de Português Brasileiro (PB), residentes no sul do país, no sul do Rio Grande do Sul. Os dados estão vinculados a um projeto de pesquisa aprovado pelo Comitê de Ética sob o número 33301814.4.0000.5339; os responsáveis pelas crianças, sujeitos desta pesquisa, consentiram com sua participação no estudo e assinaram o TCLE. Em entrevistas individuais com as crianças, os dados foram coletados por meio de nomeação espontânea a partir de gravuras e também por fala espontânea em diálogo com a pesquisadora. Todas as crianças entrevistadas foram incluídas na amostra por não terem sido diagnosticadas com déficit auditivo e neurológico.

Na investigação sobre a construção gradativa do sistema fonológico alvo da aquisição, foi posto o foco na emergência de segmentos consonantais e na variabilidade observada na ocupação de seu espaço fonético-fonológico.

Para referência na descrição e na análise da fonologia das crianças cujos dados são discutidos no presente trabalho, traz-se, em (5), o inventário de fonemas consonantais do Português, alvo da aquisição para crianças brasileiras.

(5) Sistema fonológico consonantal alvo da aquisição para crianças brasileiras

\begin{tabular}{|c|c|c|c|c|c|c|c|}
\hline \multirow[b]{3}{*}{ PLOSIVA } & LABIAL & \multicolumn{4}{|c|}{ CORONAL } & \multicolumn{2}{|c|}{ DORSAL } \\
\hline & & Anterior & \multicolumn{3}{|c|}{ Não anterior } & & \\
\hline & p b & $t \quad d$ & & & & k & g \\
\hline FRICATIVA & $f \quad v$ & $\mathrm{~s}$ & $\int$ & 3 & & & \\
\hline NASAL & $\mathrm{m}$ & $n$ & & & $\mathrm{n}$ & & \\
\hline LÍQUIDA LAT & & I & & & $\kappa$ & & \\
\hline NÃO-LAT & & $r$ & & & & & $\mathbf{R}$ \\
\hline
\end{tabular}

Reunidos os dados de todas as crianças, verificou-se uma variabilidade de formas fonéticas utilizadas para mapear um único segmento fonológico pertencente ao alvo da aquisição (mostrado em (5)) quase exclusivamente em duas classes de segmentos 
consonantais: de um lado, em consoantes obstruintes e, de outro, em consoantes líquidas; observou-se que a variabilidade encontrada ocorreu dentro de cada uma dessas classes (de obstruintes e de líquidas), sem haver o intercâmbio entre os segmentos dessas duas grandes classes. Os casos de variabilidade nas duas classes referidas estão expressos em (6a) e em (7a) ${ }^{3}$.

(6a) Variabilidade em formas fonéticas empregadas para representar consoantes obstruintes

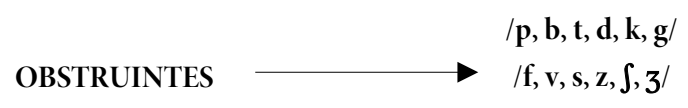

\section{VARIABILIDADE NO CORPUS}

\begin{tabular}{|c|c|}
\hline$\nabla$ & $\Delta$ \\
\hline$/ \mathrm{b} /$ & {$[b, p]$} \\
\hline$/ \mathrm{d} /$ & {$[\mathrm{d}, \mathrm{t}, \mathrm{g}]$} \\
\hline$/ \mathrm{k} /$ & {$[\mathrm{k}, \mathrm{t}]$} \\
\hline /g/ & {$[\mathrm{g}, \mathrm{k}, \mathrm{d}]$} \\
\hline$/ \mathrm{v} /$ & {$[\mathrm{v}, \mathrm{f}]$} \\
\hline$/ \mathrm{s} /$ & {$\left[\mathrm{s}, \mathrm{t}, \int\right]$} \\
\hline$|z|$ & {$\left[\mathrm{z}, 3, \mathrm{~s}, \int\right]$} \\
\hline$/ \mathrm{S} /$ & {$\left[\int, s\right]$} \\
\hline$/ 3 /$ & {$\left[3, \mathrm{z} \int, \mathrm{s}\right]$} \\
\hline
\end{tabular}

Retomando-se a noção de traços fonológicos, tem-se que as consoantes obstruintes formam uma classe por compartilharem o traço [-soante] e em torno dele estarem reunidas; as consoantes líquidas formam também uma classe por compartilharem o traço [+aproximante] e em torno dele se reunirem.

O mapeamento da variabilidade representada em (6a) no inventário de consoantes alvo mostrado em (5) evidencia que é mantida a fidelidade à classe das obstruintes, ou seja, à classe constituída pelo traço [-soante]. Veja-se em (6b) o destaque dado ao dimensionamento da classe das obstruintes.

(6b) A visão de classe na variabilidade em formas fonéticas empregadas para representar consoantes obstruentes

\begin{tabular}{|c|c|c|c|c|c|}
\hline & LABIAL & & CORONAL & & DORSAL \\
\hline & & Anterior & Não anterio & & \\
\hline PLOSIVA & $\mathbf{p}$ & $\mathrm{t}$ & & & k \\
\hline FRICATIVA & $v$ & $\mathrm{~s}$ & 3 & & \\
\hline NASAL & $\mathrm{m}$ & $\mathrm{n}$ & & $\mathbf{n}$ & \\
\hline LÍQUIDA LAT & & I & & $\kappa$ & \\
\hline NÃO-LAT & & $r$ & & & $\mathbf{R}$ \\
\hline
\end{tabular}

\footnotetext{
${ }^{3} \mathrm{Em}$ (6) e (7), na listagem das formas fonéticas que são empregadas para representar cada segmento consonantal fonológico do PB, foi incluído o registro da forma utilizada para representar o sistema alvo da aquisição.
} 
Passando à observação da variabilidade verificada no espaço fonético-fonológico das consoantes líquidas, tem-se a representação $\operatorname{em}(7)$.

(7a) Variabilidade em formas fonéticas empregadas para representar consoantes líquidas

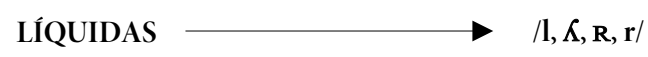

\section{VARIABILIDADE NO CORPUS}

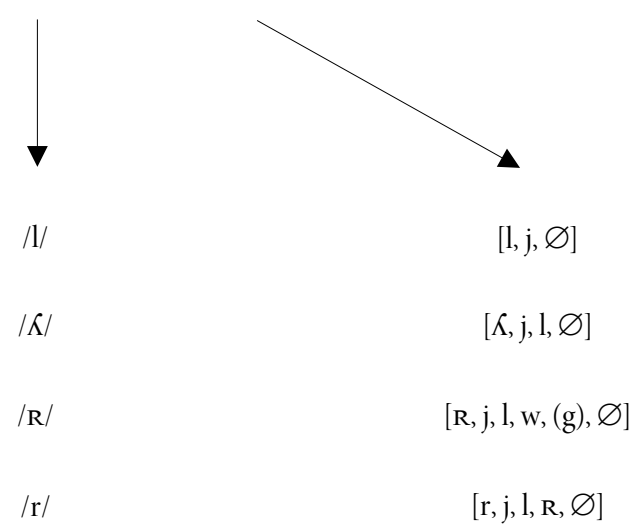

O mapeamento da variabilidade representada em (7a) no inventário de consoantes alvo mostrado em (5) evidencia que é mantida a fidelidade à classe das consoantes líquidas em oposição às outras, ou seja, há fidelidade à classe constituída pelo traço [+aproximante]. Veja-se em (7b) o dimensionamento que, na aquisição do PB, as crianças imprimem a essa classe ${ }^{4}$.

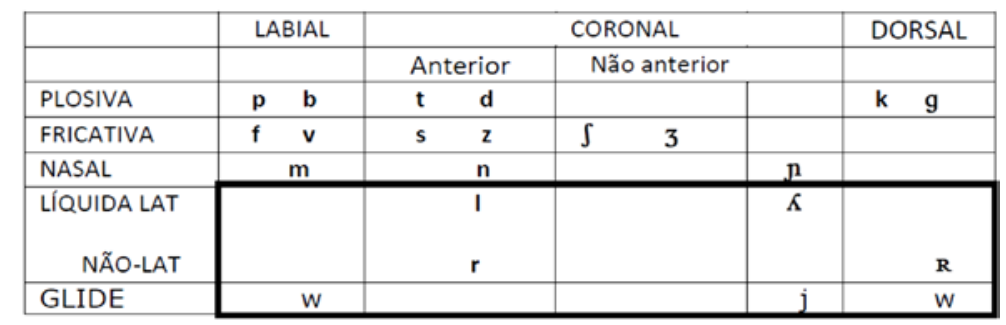

No corpus estudado, consoantes obstruintes e consoantes líquidas tiveram seu espaço fonético-fonológico variavelmente ocupado por diferentes formas fonéticas, além daquela observada no sistema alvo da aquisição. Questões, então, se impuseram; aqui formulam-se quatro:
(a) Como essa variabilidade deve ser interpretada?
(b) Como se dá a ocupação variável do espaço fonético-fonológico de um segmento por outros?
(c) Há compartilhamento de propriedades entre os segmentos-alvo com as diferentes formas fonéticas capazes de ocupar o seu espaço fonético-fonológico?

\footnotetext{
${ }^{4}$ Destaca-se que, embora o glide coronal [j] e o glide lábio-dorsal [w] não constituam fonemas no sistema consonantal do Português, são incluídos na classe dos segmentos aproximantes na representação em (7b) em razão do espaço fonético-fonológico que lhes é atribuído por crianças brasileiras no processo de aquisição das consoantes líquidas da língua.
} 
(d) As formas fonéticas que ocupam determinado espaço fonético-fonológico mapeiam exclusivamente um segmento ou são capazes de mapear uma classe/família de segmentos?

Considerando-se os casos de variabilidade registrados em (6) e (7), centrou-se a discussão deste estudo apenas nas consoantes líquidas, seguindo-se os registros mostrados em (7), focalizando-se exclusivamente a posição do segmento em onset de sílaba. Elegeram-se as líquidas por sua aquisição ser complexa, o que implica serem as consoantes de aquisição mais tardia; focalizou-se o emprego de consoantes líquidas em onset silábico, uma vez que é nessa posição da sílaba que sua emergência inicialmente se manifesta (MIRANDA, 1996; LAMPRECHT, 2004; LAZZAROTTO-VOLCÃO, 2009).

A literatura nacional e internacional sobre a aquisição fonológica (por exemplo: YAVAS et al., 1991; LAMPRECHT et al., 2004; BERNHARDT; STEMBERGER, 1998) tem proposto e utilizado critérios numéricos para subsidiar a interpretação dessa variabilidade.

De acordo com Lamprecht et al. (2004), que traz uma síntese de estudos, no Rio Grande do Sul, sobre a aquisição fonológica do Português do Brasil, a maioria dos autores considera como adquirido determinado segmento ou estrutura silábica, quando as crianças atingem a sua produção de acordo com o alvo em pelo menos $80 \%$ das possibilidades de sua ocorrência.

Seguindo-se esse critério quantitativo, traz-se o exemplo da fonologia do menino Rodrigo (idade: 2:9), cujos dados apresentam a variabilidade expressa em (8): a consoante / r/ não está adquirida, pois o percentual de emprego em conformidade com o alvo alcança o índice de $30 \%$.

(8a) Variabilidade, nos dados de Rodrigo (2:9), nas formas que representam /r/

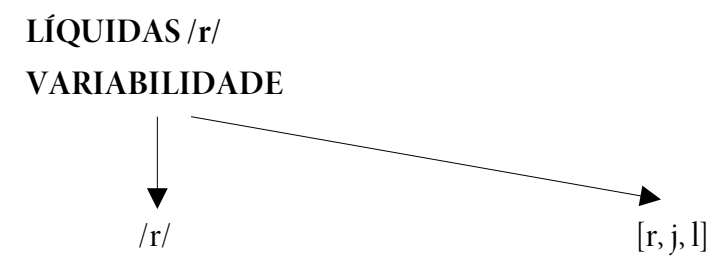

(8b) Exemplos de dados de Rodrigo (2:9)

\section{Informante}

Rodrigo (2:9)
Cadeira

Geladeira

Nariz

Orelha

Passarinho

Quero

Tesoura

Trator

Flor
Output da criança

[ka'dele]

[zela'dere]

[na'lis]

[o'leje]

[pasaTinu]

['kelu]

[t]i'zore]

[ta'toj]

['foj] 
Mas, além de verificar-se o percentual de realizações de formas fonéticas para chegar-se ao mapeamento da representação fonológica de um segmento, é preciso também pensar-se na maneira como esses dados seriam avaliados se submetidos a uma visão qualitativa. Provavelmente um maior número de informações e maior explicitação sobre o conhecimento fonológico da criança poderiam ser obtidos. Pergunta-se, então: o que se poderia dizer sobre a rótica / $\mathrm{r} /$ na fonologia do menino Rodrigo, sob uma análise qualitativa?

A ocupação variável do espaço fonético-fonológico dessa rótica por outros segmentos, nos dados do menino, pode evidenciar que essa líquida, na gramática, ainda não está estabilizada, mas também é capaz de dizer muito mais. O fato de o espaço de/r/ ser também ocupado pela líquida lateral [l] e pelo glide coronal [j] evidencia vários aspectos de seu conhecimento fonológico; entre outros, destaca-se que há o conhecimento de que:
(a) a rótica é uma consoante [+aproximante];
(b) a rótica, sendo [+aproximante], pertence a uma classe que também integra líquidas e glides e que, por isso, pode ter o seu espaço ocupado por esses segmentos;
(c) as consoantes da categoria [+aproximante] contêm uma propriedade vocálica, que as integra aos glides;
(d) a categoria [+aproximante] contrasta, na língua com a categoria [-soante].

Assim, a variabilidade da ocupação do espaço fonético-fonológico de um segmento por outros denuncia muitos aspectos do conhecimento fonológico da criança, o que decorre de a estrutura interna dos segmentos ter natureza componencial, multifacetada, que é explicitada, na gramática, por meio de traços distintivos.

Como consequência, tem-se que um segmento pode não estar estabilizado no inventário fonológico da criança em se considerando números e percentuais de ocorrência, mas, de forma indubitável, já integra a sua gramática, no sentido de que a ocupação de seu espaço fonético-fonológico já o inclui em uma classe da gramática da língua, sendo capaz de evidenciar a operação de um conhecimento fonológico composto por várias faces.

A mesma linha de entendimento pode ser aplicada à análise da ocupação de lacunas no inventário fonológico: se uma lacuna na gramática de uma criança é preenchida, esse fato mostra a categorização, em uma classe, daquele segmento cujo espaço está sendo ocupado - é o que defende Matzenauer (2018a).

Trazem-se, em (9a) e (9b), dados de duas meninas: uma com a idade de 2:9 - Márcia -, em aquisição fonológica considerada típica, e outra com a idade de 7:0 - Maria -, diagnosticada com desvio fonológico, cujos dados foram aproveitados de Matzenauer (2018b); as gramáticas das duas meninas não apresentam qualquer líquida, mas o espaço fonético-fonológico de qualquer das líquidas não fica lacunar: é ocupado pelo glide coronal [j].

(9a) Dados de Márcia (2:9) relativos à produção de palavras da língua cuja forma fonológica contém consoantes líquidas

Informante

Márcia (2:9)
Output da criança

bola

chinelo

folha

palhaço

olho

cachorro ['boje]

[ i i neju]

[fo je]

[pa'jasu]

['oju]

[ka'soju]
Alvo

/l/

/1/

/ $/$

/ $/$

/ $/$

$/ \mathrm{R} /$
Produção

[j]

[j]

[j]

[j]

[j]

[j] 


$\begin{array}{cccc}\text { quero } & {[\mathrm{keju}]} & / \mathrm{r} / & {[\mathrm{j}]} \\ \text { cadeira } & {[\mathrm{ka} \text { 'deje }]} & / \mathrm{r} / & {[\mathrm{j}]}\end{array}$

(9b) Dados de Maria (7:0) relativos à produção de palavras da língua cuja forma fonológica contém consoantes líquidas

\begin{tabular}{|c|c|c|c|c|}
\hline Informante & & Output da criança & Alvo & Produção \\
\hline \multirow[t]{8}{*}{ Maria (7:0) } & panela & [pa'neje] & $/ 1 /$ & {$[\mathrm{j}]$} \\
\hline & galo & [ga ju] & $/ 1 /$ & {$[j]$} \\
\hline & abelha & [a'beje] & $\mid K /$ & [j] \\
\hline & vermelho & [ze’meju] & $|K|$ & [j] \\
\hline & barraca & [ba jake] & $/ \mathrm{R} /$ & [j] \\
\hline & cachorro & [ta’soju] & $/ \mathrm{R} /$ & {$[\mathrm{j}]$} \\
\hline & barata & [ba'jate] & $/ \mathrm{r} /$ & {$[\mathrm{j}]$} \\
\hline & frigideira & [sizi'deje] & $/ \mathrm{r} /$ & [j] \\
\hline
\end{tabular}

Embora os dados de Márcia, em aquisição típica, e de Maria, em aquisição atípica, evidenciem a lacuna de qualquer das quatro líquidas da língua, o fato de haver o emprego de um único segmento no lugar de todas elas evidencia um conhecimento fonológico: o reconhecimento de que todas as líquidas integram uma mesma categoria na gramática. Também o fato de haver o emprego de um glide (e nunca de uma nasal ou de uma obstruinte) revela que a categoria estabelecida na fonologia das meninas é de segmento com o traço [+aproximante], e que essa classe já contrasta fonologicamente com a das consoantes nasais (que, como as líquidas, pertencem à categoria [+soante]) e com a das consoantes obstruintes, que integram a categoria [-soante].

Pode dizer-se, então, que as gramáticas das duas meninas não contêm consoantes líquidas, mas contêm a classe [+aproximante].

Assim, na aquisição fonológica pelas crianças (seja aquisição típica ou atípica, conforme sustentado em Matzenauer (2018b)), a presença de variabilidades e de lacunas (preenchidas por outros segmentos) tem de ser interpretada como expressão de estágio(s) de construção do conhecimento fonológico e essa presença é reveladora do funcionamento de sua(s) gramática(s) por meio da operação de traços ${ }^{5}$.

Tem-se, portanto, que a construção do inventário fonológico ocorre a partir de classes, que se vão especificando em segmentos. Eé dentro da classe primeiramente estabelecida que tende a haver variabilidade, ou seja, que há a tendência a um segmento ocupar o espaço fonético-fonológico de outro segmento.

Ao tratar-se da aquisição das consoantes líquidas por crianças brasileiras, a partir dos dados aqui pesquisados e também de outros estudos (por exemplo: MIRANDA, 1996; RANGEL, 1998; MATZENAUER, 2001; LAMPRECHT et al., 2004), em se verificando a ordem de emergência ter quatro estágios $(/ \mathrm{l} />/ \mathrm{R} />/ K />/ \mathrm{r} /)$ e em se observando a gradual ocupação dos espaços fonéticosfonológicos dessas consoantes, parece poder pensar-se na ativação também gradual de traços pela continuada especificação de categorias da gramática fonológica. Considera-se que a categoria das líquidas, no inventário de consoantes do Português, é determinada primeiramente pelo traço [+aproximante]; essa é a “Categoria 1”, conforme está apresentado em (10).

\footnotetext{
${ }^{5}$ Embora não seja o foco deste estudo, reconhece-se a importância de análises acústicas para a observação de detalhes fonéticos nos segmentos que podem ocupar o espaço fonético-fonológico de outros, visto que podem evidenciar contrastes encobertos, os quais podem ser reveladores de avanço do conhecimento fonológico da criança - sobre contrastes encobertos, veja-se Berti (2010).
} 
Em (10), exemplifica-se simplificadamente a gradual ativação de traços que dá origem à emergência das quatro consoantes líquidas do Português. O graduamento aqui exemplificado apresenta cinco etapas ou níveis.

(10) Especificação gradual das categorias das consoantes líquidas na gramática fonológica das crianças ${ }^{6}$

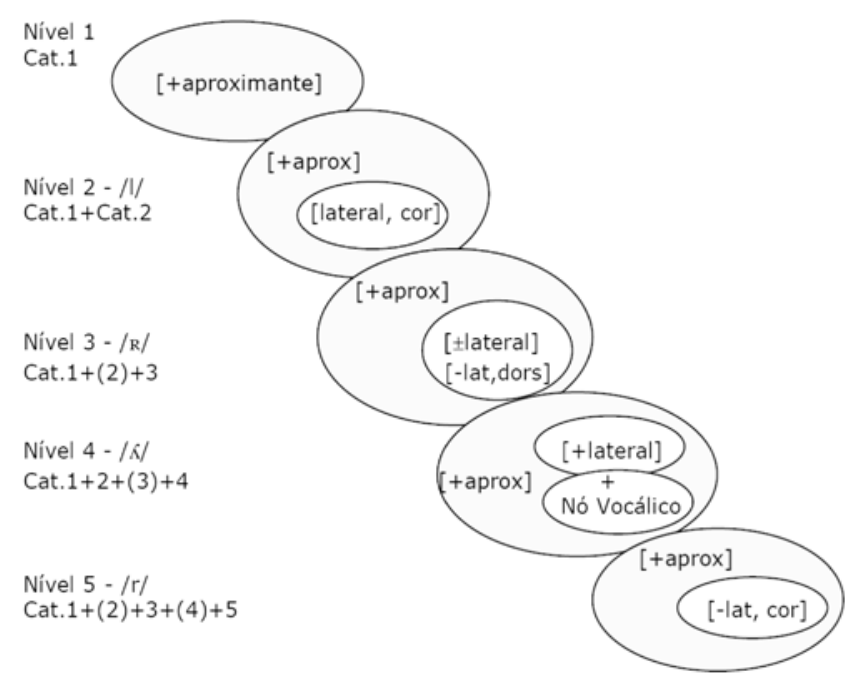

A determinação dessa classe, com a ativação gradual e coocorrente de traços fonológicos, desde logo prediz que, em caso de variabilidade durante a aquisição da fonologia, segmentos dela integrantes poderão ocupar o espaço fonético-fonológico uns dos outros.

Embora a especificação das categorias das consoantes líquidas, na gramática de crianças falantes nativas de PB, mostre a tendência a ocorrer no ordenamento mostrado em (10), em cinco níveis, nem todas as categorias de emergência mais tardia exigem, ao se considerar a ativação de traços fonológicos, a presença de categorias de níveis apresentados como anteriores. Por isso, em (10), na identificação dos níveis, o número correspondente a algumas categorias é mostrado entre parênteses. Esse fato prediz que as róticas podem emergir antes das laterais (e isso efetivamente pode ocorrer; especialmente pode ser observado em casos de aquisição fonológica atípica - veja-se Mota (1996)).

A formalização em (10), proposta deste artigo, representando o estabelecimento fonológico da classe em estágio anterior à especificação dos segmentos que nela se integram, possibilita ainda mais duas predições relevantes para a aquisição fonológica de crianças brasileiras:

(a) um segmento com a propriedade [+aproximante] tende a ocupar o espaço fonético-fonológico de qualquer líquida (e isso efetivamente ocorre, especialmente em se considerando o glide coronal [j] $)^{7}$;

(b) a líquida lateral /1/ tende a ocupar o espaço fonético-fonológico de qualquer líquida (e isso efetivamente também ocorre); o comportamento inverso tem ocorrência muito restrita - pode ser observado como variabilidade no processo desenvolvimental de estabelecimento do grupo de consoantes que integram a classe fonológica das líquidas.

\footnotetext{
${ }^{6}$ A “Categoria 2", com a ativação do traço [lateral] - aqui ainda monovalente -, implica a coocorrência do traço [+aproximante] com o traço [+consonantal]. É na "Categoria 3" que o traço [lateral] assume a característica da binaridade. Na "Categoria 4", à estrutura da consoante [+lateral], soma-se um Nó Vocálico, atribuindo uma articulação secundária vocálica ao segmento: emerge a lateral palatal / $/$.

${ }^{7}$ Pode também ocorrer o emprego do glide lábio-dorsal $[\mathrm{w}]$ no espaço fonológico de uma consoante líquida. Em crianças falantes nativas de PB, o glide [w] mostra emprego muito mais restrito do que o do glide coronal [j]: o glide [w] tende a ocupar o espaço da líquida dorsal/R/ou de outra líquida em contexto de vogal dorsal.
} 
Lazzarotto-Volcão (2009), com a proposição de um modelo construído a partir de princípios fonológicos, seguindo Clements (2009 [2005]), e a partir de dados empíricos da aquisição fonológica típica, capta não apenas a emergência gradual de contrastes no processo de desenvolvimento do inventário fonológico por crianças falantes nativas de Português, mas também a formação de classes naturais.

O Modelo Padrão de Aquisição de Contrastes - PAC, de Lazzarotto-Volcão (2009), representa o processo de integralização do inventário fonológico consonantal de crianças brasileiras em quatro estágios, expressos na formalização em (11), em cores diferentes.

(11) Formalização das etapas de aquisição fonológica segundo o PAC (LAZZAROTTO-VOLCÃO, 2009, p. 119)

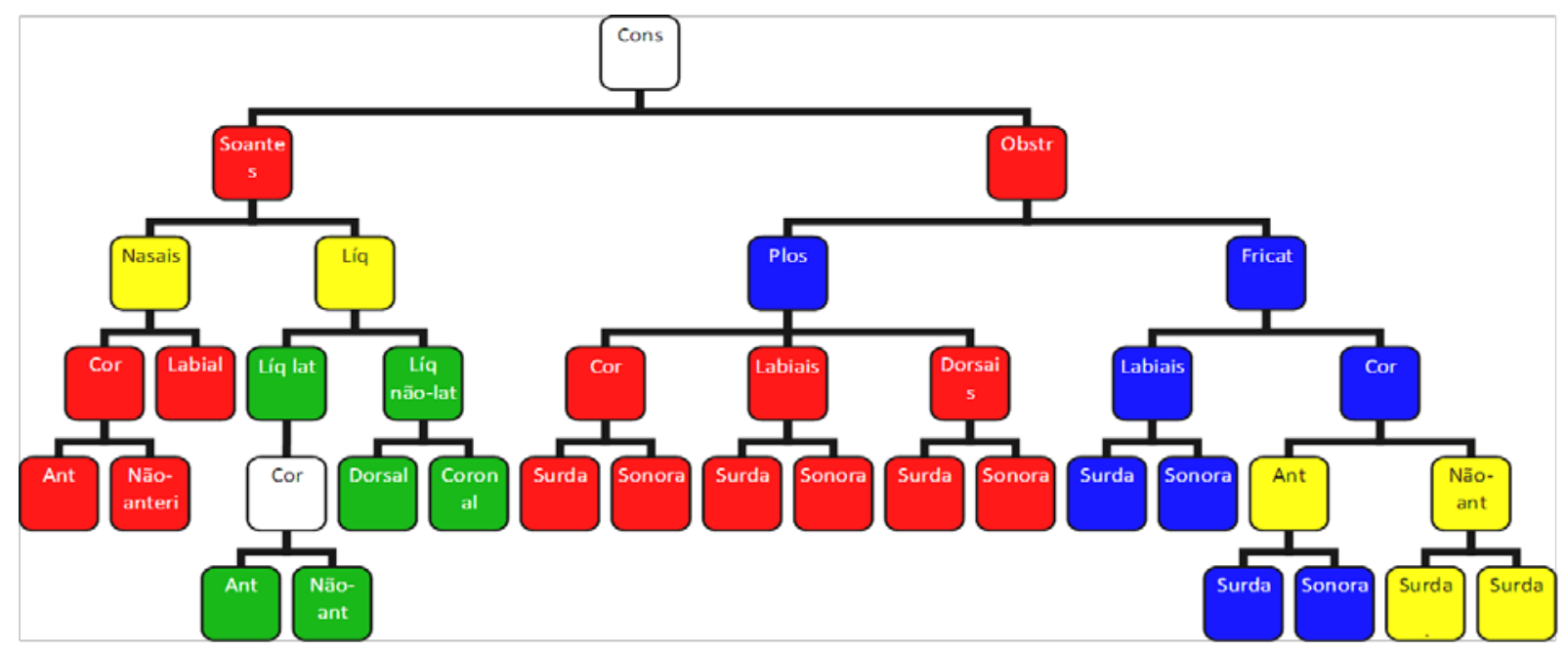

\footnotetext{
$1^{2}$ etapa da aquisiç̣̂̃o - ate 200

$2^{2}$ etapa da aquisiçăio -1.8 a $2: 6$

$3^{3}$ etapa da aqquisiçăo $-2.8-\underline{3.00}$

4' etapa da aq̣uisiçào $-3.4-4.2$

Contrastes adquiridos

Contrastes em aquisçẫo

Contrastes ausentes
}

O PAC, cuja ideia basilar consiste em explicar o funcionamento do sistema fonológico infantil a partir de coocorrências de traços, as quais são constitutivas de classes naturais de segmentos, apresenta a reinterpretação de aspectos da teoria em que buscou suporte e considera sobretudo o Princípio de Robustez dos traços na função de estabelecer contrastes na língua.

Com esse suporte, o PAC apresenta a virtude de não apenas poder subsidiar a descrição e a análise da aquisição fonológica considerada típica, mas também de oferecer as bases para a análise e a classificação de Desvios Fonológicos. Referem-se, dentre outras, algumas das vantagens do PAC na interpretação do fenômeno da aquisição da fonologia:

(a) consegue descrever e analisar o desenvolvimento do inventário consonantal em processo de aquisição fonológica típica e atípica;

(b) consegue analisar e representar como a criança preenche os espaços fonológicos ainda não adquiridos; 
(c) representa as classes naturais presentes no sistema;

(d) identifica as coocorrências de traços ativas na gramática;

(e) é capaz de oferecer subsídios para o diagnóstico de desvio fonológico;

(f) é capaz de prever possibilidades para o planejamento da terapia fonoaudiológica, a partir do momento em que capta padrões da língua-alvo e em que utiliza princípios fonológicos propostos para as línguas, também válidos para a análise da aquisição dessas línguas.

O Modelo PAC evidencia com clareza que, dentre as consoantes soantes, as líquidas, tópico de discussão no presente estudo, formam uma classe. Veja-se (12), em que a classe das líquidas se mostra destacada por uma forma retangular vertical na formalização do PAC, proposto por Lazzarotto-Volcão (2009).

(12)

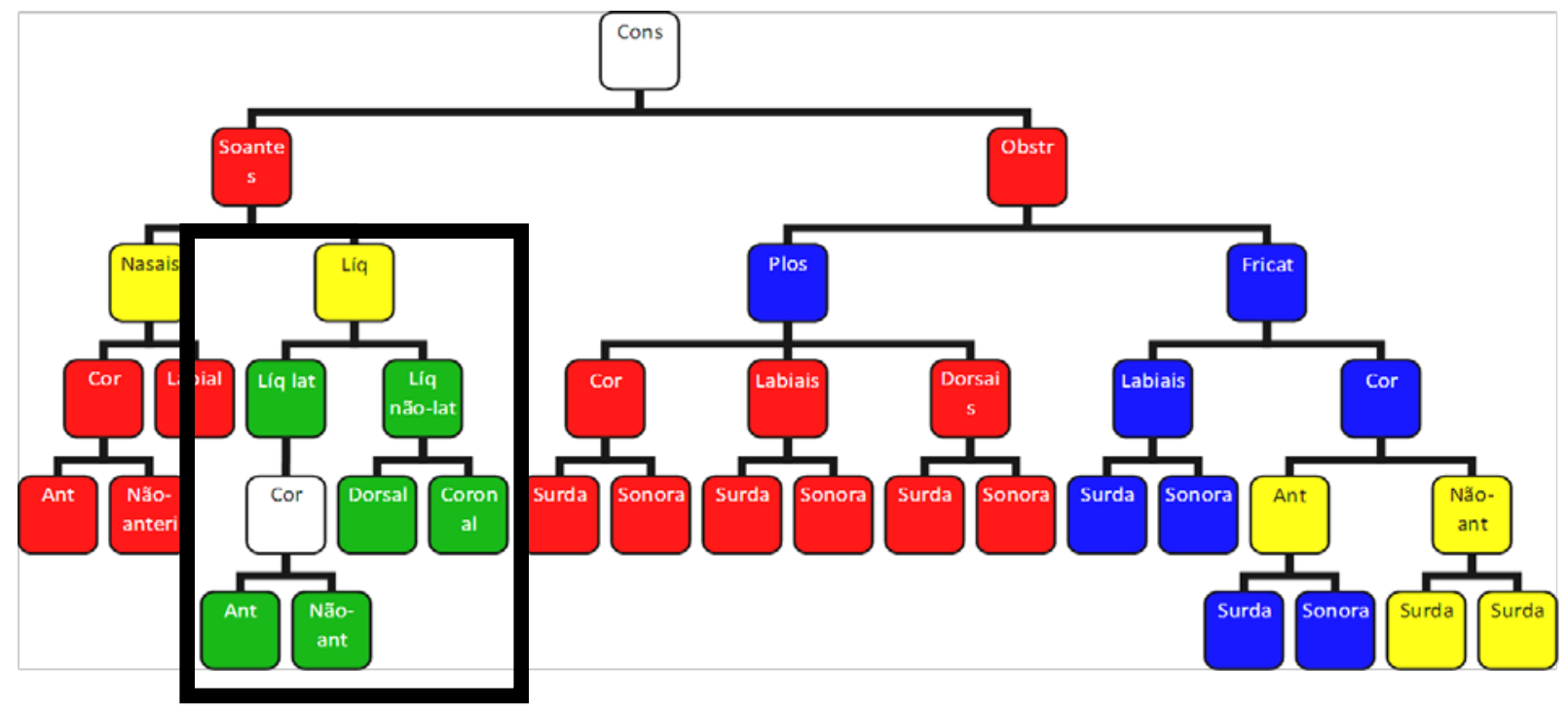

Retomando a questão dos traços como determinantes de classes fonológicas e, consequentemente, determinantes das possibilidades de variabilidade entre segmentos em estágios da aquisição fonológica, os dados aqui expostos apontam para o comportamento diferenciado dos traços nos movimentos de variabilidade que caracterizam o processo gradual de construção do sistema consonantal. Um desempenho diferente entre os traços também foi verificado no preenchimento de lacunas segmentais, em estágios iniciais da aquisição fonológica, por Matzenauer (2018a).

Os dados empíricos de variabilidade e de preenchimento de lacunas nos estágios mais precoces de aquisição conduzem à interpretação de ação diferenciada, entre os traços, no papel de reunir segmentos em uma classe: alguns traços mostram ter maior força de agregação ou nucleação de segmentos do que outros. Este entendimento foi proposto em Matzenauer (2018a): o papel agregativo é cumprido, prevalentemente, pelo traço [soante] e, depois desse, considerando-se a coocorrência com o valor [+soante], pelo traço [aproximante]. Essa proposição foi feita com o suporte de dados da aquisição fonológica, dados de empréstimos linguísticos e dados relativos a fatos da diacronia do Latim ao Português.

Nos dados de aquisição fonológica referidos no presente artigo, ficou claro que a variabilidade de formas fonéticas usadas para representar um mesmo segmento fonológico consonantal constitui classes em torno do traço [-soante] e do traço [+aproximante] ${ }^{8}$.

\footnotetext{
${ }^{8}$ A preservação dos valores do traço [-soante] e do traço [+aproximante] ocorreu nos corpora de todas as trinta crianças brasileiras cujos dados foram analisados no presente estudo.
} 
Como o papel agregador desses traços não é exclusivo do fenômeno da aquisição, conforme acima referido, a título de exemplificação dos movimentos verificados nas fonologias das línguas, retomam-se aqui os dados de Matzenauer (2018a), sobre a ocupação de espaços segmentais que são lacunares em uma língua quando toma empréstimos de outra cujo inventário fonológico contém maior número de consoantes. A pergunta que se fez pertinente no estudo citado foi se, na ocupação de espaços lacunares de uma língua, os segmentos escolhidos para cumprir essa função mantêm preservados os valores dos traços [-soante] e do traço [+aproximante] como formadores de classes, assim como ocorre no inventário fonológico em construção na aquisição da linguagem.

A busca da resposta levou ao exame de empréstimos de consoantes do Inglês ao Havaiano, conforme mostra a Seção 3.

\section{CLASSES DE SEGMENTOS EM DADOS DE EMPRÉSTIMOS}

A partir do entendimento de que o contato entre sistemas linguísticos oferece condições para a ocorrência de empréstimos lexicais, fenômeno que implica, no mais das vezes, alterações fonológicas, morfológicas ou semânticas, foi feita uma observação sobre ocorrências relativas ao plano fonológico da língua por meio do exame de empréstimos do Inglês tomados pelo Havaiano, relatados por Gussenhoven e Jacobs (1998). O interesse de se tomarem dados do Havaiano reside no fato de seu sistema consonantal contar com apenas oito segmentos, enquanto a fonologia do Inglês soma 24 consoantes (HAMMOND, 1999).

Em (13a) é mostrado o sistema consonantal do Havaiano e, em (13b), o sistema consonantal do Inglês.

(13a) Sistema Consonantal do Havaiano (GUSSENHOVEN; JACOBS, 1998, p. 39)

\begin{tabular}{|l|c|c|c|c|c|}
\hline & LABIAL & \multicolumn{2}{l|}{ CORONAL } & DORSAL & GLOTAL \\
\hline & & Anterior & $\begin{array}{c}\text { Não } \\
\text { anterior }\end{array}$ & & \\
\hline PLOSIVA & $\mathbf{p}$ & & & $\mathbf{k}$ & ? \\
\hline FRICATIVA & & & & & h \\
\hline NASAL & $\mathbf{m}$ & $\mathbf{n}$ & & & \\
\hline LÍQUIDA & & $\mathbf{l}$ & & & \\
\hline GLIDE & $\mathbf{w}$ & & & & \\
\hline
\end{tabular}

(13b) Sistema Consonantal do Inglês (HAMMOND, 1999, p. 5) ${ }^{9}$

\begin{tabular}{|c|c|c|c|c|c|c|}
\hline & LABIAL & \multicolumn{3}{|c|}{ CORONAL } & DORSAL & \multirow[t]{2}{*}{ GLOTAL } \\
\hline & & $\begin{array}{l}\text { Anterior } \\
\text { não distr. }\end{array}$ & $\begin{array}{c}\text { Anterior } \\
\text { distr. }\end{array}$ & $\begin{array}{c}\text { Não } \\
\text { anterior }\end{array}$ & & \\
\hline PLOSIVA & p $\quad$ b & & $t$ & & k & \\
\hline FRICATIVA & f $v$ & б & s & $\int$ & & h \\
\hline AFRICADA & & & & ts $d 3$ & & \\
\hline NASAL & $\mathrm{m}$ & & $n$ & & I & \\
\hline $\begin{array}{r}\text { LÍQUIDA LAT } \\
\text { NÃO LAT }\end{array}$ & & & $\begin{array}{l}\mathrm{I} \\
\mathrm{r}\end{array}$ & & & \\
\hline GLIDE & w & & & j & w & \\
\hline
\end{tabular}

Em (14), são mostrados exemplos de itens lexicais emprestados do Inglês pelo Havaiano, bem como a explicitação da ocupação dos espaços segmentais lacunares que esses empréstimos implicam; também são desenhadas as classes de segmentos constituídas pelo preenchimento de lacunas existentes no sistema consonantal do Havaiano ao ser comparado com o do Inglês.

${ }^{9} \mathrm{O}$ glide /w/, segmento consonantal do Inglês, está duplamente representado em (13b) por ter natureza lábio-velar. 
(14a) Exemplos de dados: empréstimos do Inglês para o Havaiano (GUSSENHOVEN; JACOBS, 1998, p. 43)

\begin{tabular}{|c|c|c|}
\hline Inglês & Output em Inglês & Output em Havaiano \\
\hline Ticket & [trkit] & [kikiki] \\
\hline Soap & [səup] & [kope] \\
\hline Beer & [bıə] & [pia] \\
\hline Brush & {$\left[\operatorname{br} \Lambda \int\right]$} & [palaki] \\
\hline Rice & [raIs] & [laiki] \\
\hline Flour & [flavo] & [palaoa] \\
\hline thousand & [Өauzənd] & [kaokani] \\
\hline Story & [sto:ri] & [kole] \\
\hline Bell & [beł] & [pele] \\
\hline
\end{tabular}

Os dados em (14a) evidenciam que os espaços fonológicos de segmentos presentes no sistema do Inglês, mas ausentes no Havaiano, são ocupados por consoantes que originalmente integram este sistema, que contém apenas oito consoantes. A relação entre os segmentos do Havaiano que representam consoantes exclusivas do Inglês ${ }^{10}$ aparece em (14b).

(14b) Empréstimos do Inglês: outputs que representam os segmentos lacunares no Havaiano ${ }^{11}$

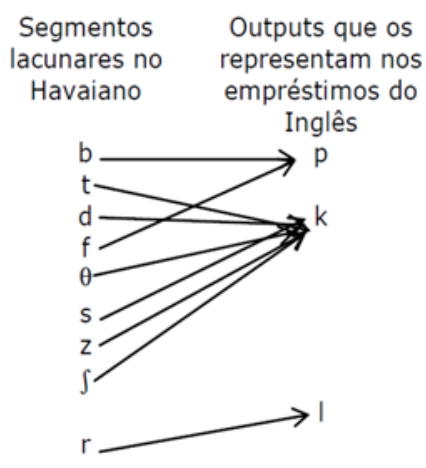

Em (14c) é apresentado o funcionamento do sistema consonantal do Havaiano, considerada a ocupação dos espaços fonológicos na representação, nos outputs, das consoantes presentes na fonologia do Inglês, mas não na do Havaiano.

\footnotetext{
${ }^{10}$ Denominam-se consoantes "exclusivas" do Inglês aquelas que estão ausentes do sistema do Havaiano, na comparação particular entre o Inglês e o Havaiano.

${ }^{11}$ Os segmentos listados como presentes no Inglês e lacunares no Havaiano são apenas aqueles presentes nos exemplos apresentados por Gussenhoven e Jacobs (1998).
} 
(14c) Funcionamento do Sistema Fonológico do Havaiano em relação aos empréstimos do Inglês: outputs que representam os segmentos lacunares no Havaiano

\begin{tabular}{|c|c|c|c|c|c|}
\hline & LABIAL & \multicolumn{2}{|l|}{ CORONAL } & \multirow{2}{*}{ DORSAL } & \multirow{2}{*}{ GLOTAL } \\
\hline & & Anterior & Não anterior & & \\
\hline PLOSIVA & $p \leftarrow b$ & $t \quad d=$ & & $k$ & $?$ \\
\hline FRICATIVA & $f \mid$ & $s \longrightarrow$ & J & & h \\
\hline NASAL & $\mathrm{m}$ & $\mathbf{n}$ & & & \\
\hline \multirow[t]{2}{*}{ LÍQUIDA } & & $I_{A}$ & & & \\
\hline & w & $\mathrm{r} \uparrow$ & & & \\
\hline
\end{tabular}

A organização do espaço fonológico que o Havaiano promove ao receber empréstimos do Inglês determina o funcionamento de classes de segmentos, as quais se encontram dimensionadas em (14d).

(14d) Dimensionamento de classes de segmentos, a partir da ocupação, nos empréstimos do Inglês, de espaços fonético-fonológicos lacunares no Sistema Fonológico do Havaiano

\begin{tabular}{|c|c|c|c|c|c|}
\hline & LABIAL & \multicolumn{2}{|l|}{ CORONAL } & \multirow{2}{*}{ DORSAL } & \multirow[t]{2}{*}{ GLOTAL } \\
\hline & & Anterior & Não anterior & & \\
\hline PLOSIVA & $\mathrm{p}-\mathrm{b}$ & $\mathrm{d}$ & 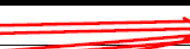 & $\mathrm{k}$ & $?$ \\
\hline FRICATIVA & $\mathrm{f}$ & $s-2$ & $5=$ & & h \\
\hline NASAL & $\mathrm{m}$ & $\mathrm{n}$ & & & \\
\hline LÍQUIDA & & $I_{A}$ & & & \\
\hline & $w$ & $r 1$ & & & \\
\hline
\end{tabular}

Os movimentos que os empréstimos que o Havaiano faz do Inglês implicam fidelidade aos valores do traço [soante], tanto em seu valor [-soante], quanto em seu valor [+soante]. Considerada a formação de uma classe [-soante], opõem-se os traços [labial] e [dorsal], este chamando para o ponto [dorsal] os segmentos coronais do Inglês; nos empréstimos referidos, portanto, podem ser violados traços de ponto e de vozeamento. Na classe [+soante], é mantida a fidelidade ao traço [+aproximante], bem como ao traço de ponto [coronal].

O exemplo aqui exposto relativamente ao comportamento dos empréstimos que movimentam a fonologia a partir de espaços fonológicos lacunares - considerando-se o sistema consonantal do Havaiano em contato com o do Inglês - apresenta similaridade com o que se observa no movimento de variabilidade e de ocupação dos espaços fonológicos lacunares durante o processo de aquisição da linguagem pelas crianças, de acordo com a apresentação na Seção 2: há um comportamento diferenciado dos traços, com um destaque para a fidelidade ao traço [soante] e ao traço [+aproximante]; estes traços funcionam como núcleos atratores ou agregadores na formação de classes de segmentos. Os movimentos parecem ocorrer em classes determinadas majoritariamente por esses traços e, portanto, esse fato implica diferença entre traços na força de constituição de classes de segmentos.

Essa fidelidade ao traço [soante] e ao traço [+aproximante] é indicativa de que os segmentos se movimentam e se alteram em uma classe natural formada (ou agregada) em torno desses traços.

\section{DISCUSSÃO DOS DADOS}

Verificam-se generalizações nos movimentos que dizem respeito à variabilidade dos segmentos e à ocupação de espaços lacunares em inventários fonológicos, ao se considerar o processo de aquisição típica da linguagem e, pelos dados mostrados na Seção 3, ao se observar o tratamento de empréstimos - e os traços são determinantes de tais movimentos. 
$\mathrm{Na}$ fonologia das crianças, os movimentos que indicam variabilidade na representação de um único segmento fonológico (assim como os movimentos para o preenchimento dos espaços que são lacunares em comparação com o sistema-alvo) parecem estar mostrando que, antes mesmo de emergirem como unidades integrantes do inventário fonológico, os segmentos (ou propriedades deles) já são percebidos e categorizados na gramática, ou seja, recebem um rótulo com base em determinadas pistas (fonéticas) e traços (fonológicos), que os colocam em uma classe. Essa categorização parece estar prioritariamente sendo feita pelo traço [soante] e pelo traço [+aproximante]: o traço [soante] (tanto o valor [-soante], como o valor [+soante]) e o traço [+aproximante] têm a força de congregar segmentos, reunindo-os em uma classe, na qual podem movimentar-se até que cada segmento ocupe o seu lugar em consonância com a gramática alvo.

Tem-se um exemplo da força agregativa do traço [+aproximante] no caso de uma criança cuja fonologia ainda não integre a líquida rótica /R/, sendo que o espaço dessa consoante é ocupado por [l], e não por qualquer outro segmento, como [t] ou [n], por exemplo (ex.: cacho/R/o $\rightarrow$ cacho[l] u). Interpreta-se que a criança percebe e categoriza $\mathrm{o} / \mathrm{R} /$ (ou propriedades do /R/) como uma unidade pertencente à classe [+aproximante]. Portanto, vê-se que $\mathrm{o} / \mathrm{R} /$ pode não estar integrado à sua fonologia, mas já é interpretado como parte da gramática, graças à força agregativa e, consequentemente, categorizadora dos traços, aqui, particularmente, exercida pelo traço [+aproximante]. Falta a essa criança a ativação dos outros traços que, de forma coocorrente, irão constituir o /R/ e, consequentemente, irão promover o contraste com aquele segmento que ocupa o seu espaço fonológico e também irão estabelecer o contraste com todos os outros segmentos que compõem o inventário da língua.

Destaca-se que o traço [soante] e o traço [+aproximante] mostraram força agregativa não apenas no processo de aquisição fonológica, mas também ao se observarem os preenchimentos de lacunas de segmentos no tratamento de empréstimos (veja-se o exemplo do Havaiano, mostrado na Seção 3): processos que alteram segmentos ou ocupam espaços de outros segmentos parecem manter prioritariamente a fidelidade a esses traços.

Vale ainda considerar que o traço [soante] e o traço [+aproximante] atuam em coocorrência com outros traços. Na aquisição fonológica, é com a coocorrência desse traço que se vai dividindo uma classe maior em subclasses e, nesse encaminhamento, vão sendo construídas as classes naturais que caracterizam o sistema em aquisição; Lazzarotto-Volcão (2009) defende e exemplifica esse comportamento coocorrente de traços no processo de aquisição fonológica - veja-se o exemplo da formalização em (12).

Os dados também são capazes de mostrar - embora o presente artigo não inclua análise com esse foco - que, além do traço [soante] e do traço [+aproximante], outros traços cumprem o mesmo papel agregativo, ou seja, o papel de formador de classes. No entanto, os traços mostram diferenças quanto a essa força agregativa e esse fato os coloca em níveis diferenciados: alguns traços mostram maior força agregativa do que outros, tanto ao se verificarem os casos de aquisição fonológica, como os de empréstimos, em conformidade com os exemplos trazidos na Seção 3. É pertinente, portanto, propor-se uma hierarquia relativa à função dos traços de congregar segmentos em classes, identificando-a como uma 'Escala de Agregação'. Essa Escala pode ser capaz de explicitar a força dos traços no cumprimento do papel de agregar segmentos para a constituição de classes naturais ${ }^{12}$.

A 'Escala de Agregação’ que se propõe, com o suporte em dados de aquisição da fonologia e de tratamento de empréstimos, é mostrada em $(15)^{13}$.

${ }^{12}$ Essa escala foi originalmente proposta por Matzenauer (2018a), sendo rediscutida por Matzenauer (2018b).

${ }^{13} \mathrm{O}$ traço [nasal] está incluído no Nível 2 da Escala, na coocorrência de traços [-aproximante, +soante]. 
(15) 'Escala de Agregação’

\begin{tabular}{|c|c|c|}
\hline Nível & Traço & Coocorrência \\
\hline 1 & {$[ \pm$ soante $]$} & \\
\hline 2 & [ \pm aproximante] & / [+soante] \\
\hline \multirow[t]{3}{*}{3} & [labial] & \\
\hline & [coronal] & \\
\hline & [dorsal] & \\
\hline 4 & [ \pm contínuo] & / [-soante $]$ \\
\hline 5 & {$[ \pm \mathrm{vOz}]$} & / [-soante $]$ \\
\hline 6 & [ \pm anterior] & $/[$-soante $]$ \\
\hline 7 & Outros traços & \\
\hline
\end{tabular}

Essa ‘Escala de Agregação’ pode conduzir a uma predição relevante para o funcionamento de inventários fonológicos, incluindo aqueles que caracterizam diferentes estágios do processo de aquisição de uma língua pelas crianças: é capaz de predizer que, em um sistema linguístico, as relações entre segmentos fonológicos deverão implicar operações que tenderão a manter inalterados os valores dos traços dos níveis mais altos da 'Escala de Agregação', preservando as classes naturais por eles constituídas.

Observando-se os três mais altos níveis da 'Escala de Agregação', verificam-se diferenças entre os traços que representam propriedades articulatórias: quando vinculados ao parâmetro de modo de articulação dos segmentos, os traços parecem mostrar maior força agregativa do que aqueles vinculados ao parâmetro de ponto de articulação; mais abaixo na escala está o traço que categoriza a propriedade do vozeamento, com menor agregativa.

A 'Escala de Agregação' em (15) parece atender aos dados de aquisição da fonologia e de tratamento de empréstimos examinados neste artigo, mas precisa ser testada por meio da análise de dados de aquisição de outros sistemas fonológicos, como também do comportamento dos processos que integram as fonologias de diferentes línguas. Sendo confirmada a predição feita pela 'Escala de Agregação', processos fonológicos que implicarem, por exemplo, alteração do traço [ \pm anterior] serão muito mais frequentes nas línguas do que os processos que implicarem alteração do traço [ \pm soante].

Ao falar-se em uma 'Escala de Agregação', é relevante salientar que sua natureza é diferente da 'Escala de Robustez', proposta por Clements (2009). Ambas mostram semelhanças, porque são compostas por traços em sua função fonológica, mas têm de apresentar diferenças, porque a noção a elas subjacente é distinta: enquanto a 'Escala de Robustez' está fundada na noção de contraste entre segmentos, a 'Escala de Agregação' tem base na noção de classes de segmentos.

Para comparação com a 'Escala de Agregação’ em (15), apresenta-se em (16) a 'Escala de Robustez', proposta por Clements (2009, p. 46-47).

(16)'Escala de Robustez’, proposta por Clements (2009) 


$\begin{array}{lc} & {[ \pm \text { soante }]} \\ \text { a) } & {[\text { labial }]} \\ & {[\text { coronal }]} \\ & {[\text { dorsal }]} \\ & \\ \text { b) } & {[ \pm \text { contínuo }]} \\ & {[ \pm \text { anterior }]} \\ & \\ \text { c) } & {[ \pm \text { voz }]} \\ & {[ \pm \text { nasal }]} \\ \text { d) } & {[\text { glotal }]} \\ & \\ \text { e) } & \text { Outros }\end{array}$

Destaca-se a observação de que o traço [ \pm soante] é o mais robusto ao cumprir o papel de contrastar segmentos, como mostra a sua presença no nível (a) da 'Escala de Robustez', e também é o que apresenta maior força agregativa, ocupando o topo da 'Escala de Agregação'. Os traços de ponto também estão altos nas duas escalas, mas há diferenças entre os níveis em que estão os outros traços.

Por considerar-se que as duas escalas atuam na constituição e no funcionamento de inventários fonológicos, defende-se a sua relevância. A ‘Escala de Agregação’ vem somar informação ao oferecer mais uma perspectiva sobre o entendimento do processo de aquisição fonológica, sobre o exame de casos de empréstimos linguísticos e, segundo Matzenauer (2018a), sobre a análise dos movimentos que mostram as línguas em seu continuum evolutivo.

\section{CONSIDERAÇÕES FINAIS}

A construção e o funcionamento da gramática, tanto ao tratar-se de inventários fonológicos, como de processos fonológicos, são condicionados por traços. Evidências, nesse sentido, foram aqui apontadas por meio de dados de aquisição da linguagem e de empréstimos linguísticos.

Os dados que integraram este estudo também indicaram haver diferença entre os traços em se considerando a sua força para agregar segmentos na constituição de uma classe, cuja relevância é fundamental na gramática, uma vez que a noção de classe está subjacente aos movimentos que se operam nos segmentos. Verificados padrões nessas diferentes forças dos traços, foi possível propor o funcionamento de uma 'Escala de Agregação', considerando-se a função dos traços de constituir classes naturais. Essa proposição tem fundamento ao captar generalizações relativas a uma atividade prevalente nas fonologias das línguas, que é a de reunir segmentos em inventários e em processos fonológicos, expressos neste artigo por meio da ocorrência de variabilidade e de preenchimento de lacunas no preenchimento de espaços fonético-fonológicos, tanto na aquisição fonológica, como no tratamento de empréstimos. Entende-se que a agregação de segmentos por meio de traços parece mostrar particular relevância na computação fonológica; os dados deste estudo apontam nesse sentido.

Salienta-se, mais uma vez, que, no processo de aquisição da fonologia de uma língua, a variabilidade e a ocupação de espaços ainda lacunares em comparação com o sistema-alvo são determinadas por traços e obedecem ao funcionamento de classes de segmentos. Ressalta-se, por fim, que esse fato pode ser interpretado como a operação de propriedades e traços agregativos, que têm grande importância porque oferecem a condição para que o processo de categorização fonológica venha a organizar-se. 


\section{REFERÊNCIAS}

BERNHARDT, B. M. H.; STEMBERGER, J. P. Handbook of phonological development: from a nonlinear constraints-based perspective. San Diego: Academic Press, 1998.

BERTI, L. C. Contrast and covert contrast in the speech production of children (original title: Contrastes e contrastes encobertos na produção da fala de crianças). Pró-Fono Revista de Atualização Científica, v. 22, n. 4, p. 531-536, out./dez. 2010.

CLEMENTS, G. N. The role of features in phonological inventories. In: RAIMY, E.; CAIRNS, C. E. Contemporary views on architecture and representations in phonology. Cambridge: MIT Press, 2009 [2005].

GUSSENHOVEN, C.; JACOBS, H. Understanding phonology. London: Arnold, 1998.

HAMMOND, M. The phonology of English: a prosodic optimality theoretic approach. Oxford: Oxford University Press, 1999.

HYMAN, L. M. Phonology: theory and analysis. New York: Holt, Rinehart \& Winston, 1975.

LAMPRECHT, R. R. et al. Aquisição fonológica do Português. Perfil de desenvolvimento e subsídios para terapia. Porto Alegre: Artes Médicas, 2004.

LAZZAROTTO-VOLCÃO, C. Modelo padrão de aquisição de contrastes: uma proposta de avaliação e classificação dos desvios fonológicos. 2009. 219 f. Tese (Doutorado em Letras) - Universidade Católica de Pelotas, Pelotas, 2009.

MATZENAUER, C. L. B. Restrições segmentais e prosódicas na aquisição das líquidas do Português Brasileiro e do Português Europeu. Boletim da ABRALIN, Fortaleza, v. 26, N Especial, p. 223-225, 2001.

MATZENAUER, C. L. B. A arquitetura da gramática fonológica: mais uma observação sobre traços e classes de segmentos. In: LINGUÍSTICA FORMAL I, 1., 2018, Florianópolis. Florianópolis: UFSC, 2018 a.

MATZENAUER, C. L. B. A gramática fonológica na aquisição da linguagem. In: SEMINÁRIO INTERNACIONAL DE AQUISIÇÃO DA LINGUAGEM, 1., 2018, Florianópolis. Florianópolis: UFSC, 2018 b.

MIRANDA, A. R. M. A aquisição do 'r': uma contribuição à discussão sobre seu status fonológico. 1996. 128 f. Dissertação (Mestrado em Letras) - Pontifícia Universidade Católica do Rio Grande do Sul, Porto Alegre, 1996. 
MOTA, H. B. Aquisição segmental do Português: um modelo implicacional de complexidade de traços. 1996. Tese (Doutorado em Letras) - Pontifícia Universidade Católica do Rio Grande do Sul, Porto Alegre, 1996.

RANGEL, G. de A. Uma análise auto-segmental da fonologia normal: estudo longitudinal de três crianças de 1:6 a 3:0.1998. 128 f. Dissertação (Mestrado em Letras) - Pontifícia Universidade Católica do Rio Grande do Sul, Porto Alegre, 1998.

YAVAS, M. et al. Avaliação fonológica da criança. Porto Alegre: Artes Médicas, 1991.

\section{() (1) $\circledast$}

